\title{
Correction to: Effects of growth hormone on bone modeling and remodeling in hypophysectomised young female rats: a bone histomorphometric study
}

\author{
Lysette Iglesias ${ }^{1}$. James K. Yeh ${ }^{2,3} \cdot$ Mariano Castro-Magana ${ }^{1}$ - John F. Aloia ${ }^{2,3}$
}

Published online: 27 July 2019

๑) Springer Japan KK, part of Springer Nature 2019

\section{Correction to: J Bone Miner Metab (2011) 29:159-167 https://doi.org/10.1007/s00774-010-0210-3}

The following corrections are found in the original publication of the article and corrected as below:

Figure 2 was reproduced in part from Chaudhry AA, Castro-Magana M, Aloia JF, Yeh JK (2009) Differential effects of growth hormone and alpha calcidol on trabecular and cortical bones in hypophysectomized rats. Pediatr Res 65(4):403-408 (Fig. 1).

In Table 1, femoral BMD units should be reported as mg/ $\mathrm{cm}^{2}$. In the text of the "Results" the unit of periosteal and endocortical MAR should be $\mu \mathrm{m} /$ day and BFR should be $\mu \mathrm{m}^{3} / \mu \mathrm{m}^{2} /$ day.

The correct reference \# 21 is Guevarra MS, Yeh JK, Castro Magana M, Aloia JF (2010) Synergistic effect of parathyroid hormone and growth hormone on trabecular and cortical bone formation in hypophysectomized rats. Horm Res Paediatr 73(4):248-257.

Note from the Editorial Office

There was an allegation that these publications were duplicate publications. However, these authors provided reasonable rebuttal in response to our queries and we felt that the overlaps among those papers are minor. Accordingly,

The original article can be found online at https://doi.org/10.1007/ s00774-010-0210-3.

Lysette Iglesias

lysettei@yahoo.com

1 Department of Pediatric Endocrinology, Winthrop

University Hospital, 120 Professional Building Suite 210,

Mineola, NY 11501, USA

2 Applied Bench Core Laboratory, Winthrop University Hospital, Mineola, NY 11501, USA

3 The Health Sciences Center, State University of New York at Stony Brook, Stony Brook, NY 11794, USA
JBMM decided to accept the Erratum submitted by the authors, although JBMM would like to propose that those publications should have been published in one paper.

Publisher's Note Springer Nature remains neutral with regard to jurisdictional claims in published maps and institutional affiliations. 